\title{
Tinidazole-induced fixed drug eruption: A case report
}

\author{
Sarkar M K ${ }^{1}$, Mishra R², Pandya $P^{3}$, Bansal A ${ }^{4}$, Bajhaiya B $S^{5}$, Mithun ${ }^{6}$ \\ ${ }^{1}$ Dr Manuj Kumar Sarkar, Assistant Professor, Department of Medicine, Index Medical College Hospital and Research \\ Centre, Indore, MP, India, ${ }^{2}$ Dr Rishu Mishra, ${ }^{3}$ Dr Parth Pandya, ${ }^{4}$ Dr Aastha Bansal, ${ }^{5}$ Dr Babeena Singh Bajhaiya, and ${ }^{6} \mathrm{Dr}$ \\ Mithun, ${ }^{(2-6)}$ Post Graduate Student, Department of Medicine, Index Medical College Hospital and Research Centre, \\ Indore, MP, India. All are affiliated to Index Medical College Hospital and Research Centre, Indore, MP, India.
}

Address for Correspondence: Dr Manuj Kumar Sarkar, Email: manojsarkar654321@gmail.com

\begin{abstract}
FDE is characterized by onset of oval or round erythematousmacule on the mucosa or skin. Patients may have itching and burning sensation.22 years old married female presented with complaining of burning sensation and ulceration in lower lip and erythematous well-defined macule onmuco-cutaneous junction of vagina for last two days following intake of Tinidazole $400 \mathrm{mg}$ twice daily for 1 day.FDE though not fatal, can cause cosmetic disfigurement.Fixed drug eruption in genital region is a matter of apprehension. The exact mechanism of FDE is unknown.
\end{abstract}

Keywords: Fixed Drug Eruption, Tinidazole, Nitroimidazoles

\section{Introduction}

Fixed drug eruption (FDE) is characterized by single or multiple skin lesions which occur at the same site each time the drug is administered $[1,2]$. Lesions are usually oval or round and well defined, but their severity increases with each exposure. Skin reactions are found 1 to 10 hours of ingestion of drugs. Redness and swelling appears first. They are commonly seen in perianal area, but may be found in any part of body. After healing,hyperpigmentationpersist at the site[2]. Structurally similar same group drugs shows crosssensitivity. The drug acts ashaptenand binds to basal keratinocytes, thus initiates hypersensitivity reaction $[3$, 4].

Nitroimidazoles are antimicrobial compounds having very good activityagainst anaerobic-organisms and protozoa. They are used commonly inamoebiasis, both hepatic and intestinal form. Their sidechains are different [2, 4].Nitroimidazoles are used as self medication and a number of cases of fixed drug eruption caused by nitroimidazoles are reportedasmetronidazole $[5,6,7,8$ and9],tinidazole[4,10,11 and 12], and ornidazole[2,13,14,15 and 16] etc.

\section{Case Report}

Manuscript received: $4^{\text {th }}$ July 2015

Reviewed: $11^{\text {th }}$ July 2015

Author Corrected: $18^{\text {th }}$ July 2015

Accepted for Publication: $31^{\text {st July } 2015}$
22 years old married femalepresented to the OPD (Outpatient Department) of general medicine in Index Medical College Hospital and research centre, Indore, MP, India, complaining of burning sensation and ulceration in lower lip and erythematous well-defined macule onmuco-cutaneous junction of vagina for 2 days. From historyit was found that the patient was suffering from acute gastro-enteritis for the last 3 days and she was taking tablet Tinidazole $400 \mathrm{mg} /$ day twice daily for 1 day. She was not taking any other medications. She was non-diabetic. No history of any substance abuse or other drugs. No history of sexual contact.She had lesions in lips and vaginal mucosa following ingestion of Tinidazole 6 months back.

$\mathrm{O} / \mathrm{E}$, vital signs were normal. Ulceration on the lower lipwith peripheral erythematous halo[figure: 1] was found and macule in vaginal mucosa was seen.The lesions were non tender. There was no itching orno pus discharge was present. There was no evidence of any skin involvement. Routine investigations were within normal limit.

Based on history and examination, a provisional diagnosis of Fixed Drug Eruption (FDE) due to Tinidazole was made considering the relation of the drug consumption with appearance of the lesions. She was treated with tablet dexamethasone, levocetrizine,topical cream was given containing fusidic 
acid and betamethasone, tablet Rabiprazole $20 \mathrm{mg}$ on

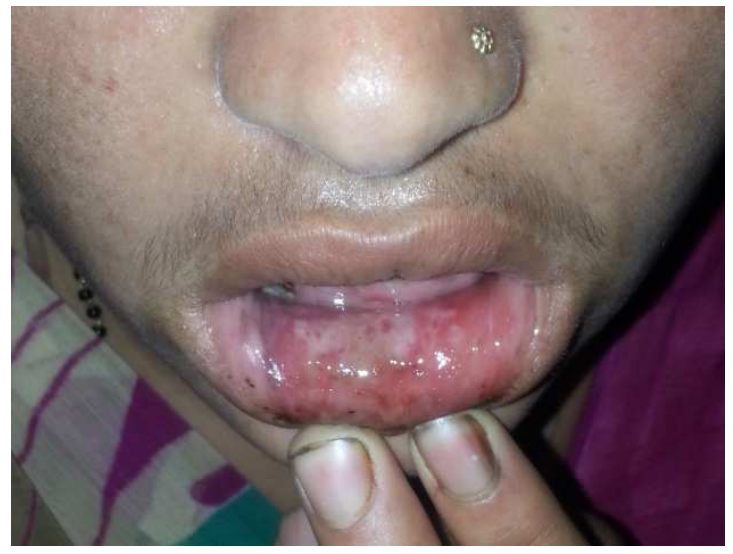

empty stomach was given.

Figure 1: Ulcerated lesion on lower lip with peripheral erythematous halo

Follow up on 10 day,all the lesions subsided and only hyperpigmentation was persisting [figure: 2]. The assessment showed probable (Score - 7) and moderate (level - 4) type of ADR as per Naranjo algorithm [17] and Hartwig scale [18] respectively.

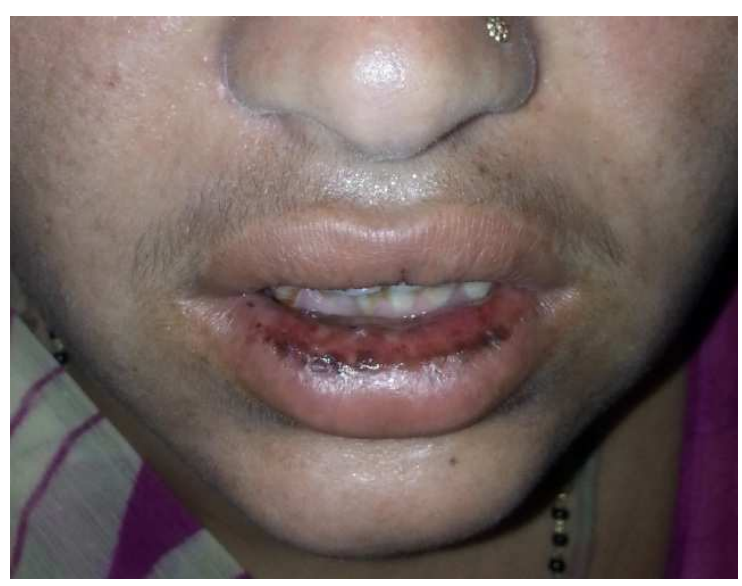

Figure 2:Hyperpigmentation of lower lip on follow up

\section{Discussion}

FDE is a type of delayed hypersensitivity mediated by CD8 cells. The drug acts as hapten and binds to basal keratinocytes, thus initiates hypersensitivity reaction and lymphocytes releases antibodies which damages basal cell [2, 13, and 14]. Oral administration causes most FDE's rather than other means.Structurally similar drug from the same group can cause fixed drug eruption, which is called cross sensitivity.

A single erythematousmacule is the commonest presentation, it may become pigmented.Typicallythey reappear at the same site, but on stoppage of the drug, they disappear, only residual hyperpigmentation can be found later. New lesions can develop on previously normal skin also [14].

21-30 years is the peak incidence of FDE and male:female are equally affected [4]. Most commonly involved sites are lips, palm and soles, genital areas. Commonlyinvolved sites as stated bySharma VK are trunk and limbs (24\%), lips alone $(20.8 \%)$ and genitalia alone (20\%), generalised (14.4\%), lips and genitalia together (11.2\%), and trunk alone $(8.8 \%)[14,19]$. 
The diagnosis of FDE is usually done based on characteristic hyperpigmentation following drug intake and persisting hyperpigmentation after improvement. Historyof drug intake and a past history of similar lesions at the same sites following intake of the same drug are important aspect of diagnosis of FDE [14].

Challenge test as oral and topical are used for confirmation of FDE.If there is no reaction with lesser dose then dose of the drug is increased up to full therapeutic dose to look for any reaction. Oral test is better than topical for confirmation of diagnosing [14].

If a person is hypersensitive to particular drug, he should avoid drugs from the same group, as he may develop FDE to those similar drugs. Testing for hypersensitivity may help us to find out other safe drugs from the same group [2]. Though challenge test are confirmatory and mandatory for diagnosis, few physicians do not attempt it [13].

Recurrence of similar lesions at same site on taking same medication is the most important history of fixed drug eruption. We did not confirm the diagnosis by oral challenge test as the patient herself gave history of similar symptoms at the same site previously also after exposure to the same drug and also she was not willing for taking the same medicine again for fear of aggravation of symptoms.

\section{Conclusion}

FDE's are uncommon adverse reaction of nitroimidazoles, treating physicians should be aware of it to diagnose and treat it on time. Fixed drug eruptions are though not fatalcan cause cosmetic disfigurement. Fixed drug eruption in genital region is a matter of apprehension. Nitroimidazoles are commonly used drugs in India and they are also taken by patients as self-medication. Whenever FDEs are seen, immediate withdrawal of the drug should be done, treatment should be started, and patients should be taught about possible adversereaction ofsuch drugs.

\section{Source of Support: Nil.}

Conflict of Interest: Nil.

NB: Written consent of the patient was taken for taking photograph.

\section{References}

1. Korkij W, Soltani K. Fixed drug eruptions - a brief review. Arch Dermatol.1984; 120:520-4.

2. Sanmukhani J, Shah V, Baxi S, Tripathi C. Fixed drug eruption with ornidazole having cross-sensitivity to secnidazole but not to other nitro-imidazole compounds: A case report. Br J ClinPharmacol. 2010 Jun; 69(6):703-704.

3. Weedon D. Skin Pathology. 2nd. London: Churchill Livingstone; 2002. The lichenoid reaction pattern ('interface dermatitis') pp. 42-3.

4. K Sangma, J Wahlang, M Marak, M Sangma, M Lyngdoh, D Brahma. Fixed Drug Eruption Due to Tinidazole: 2 Case Reports and Review of Literature.The Internet Journal of Pharmacology.2012 Volume 10 Number 1.

5. Kanwar AJ, Sharma R, Rajgopalan M, Kaur S. Fixed drug eruption due to tinidazole with cross sensitivity to metronidazole.Dermatologica. 1990; 180(4):277.

6. Thami GP, Kanwar AJ. Fixed drug eruption due to metronidazole and tinidazole without cross-sensitivity to secnidazole. Dermatology; 1998; 196: 368.

7. Arora SK. Metronidazole causing fixed drug eruption. Indian J DermatolVenereolLeprol; 2002; 68:108-9. 
8. S. Gupta, K. Alam, S. Palaian, M.M. Singh, B.C. Dwari, S. Prabhu, M. Prabhu\& P. Mishra: Metronidazole Induced Bullous Fixed Drug Eruptions: A Case Report And A Review Of Literature. The Internet Journal of Dermatology; 2007; Volume 5 Number 1.

9. Wahlang JB et al. Fixeddrug eruption due to metronidazole: review of literature and a case report. International Journal of Pharma Sciences and Research (IJPSR); March 2012; 3(3): 331-334.

10. Jafferany M, Haroon TS. Tinidazole-induced fixed drug eruption. Int J Dermatol; 1988; 27:279.

11. Bansal A, Kumari R, Ramam M. Fixed drug eruption due to cross reaction between two azoles used for different indications. Indian J DermatolVenereolLeprol; 2008; 74:81.

12. Mishra D, Mobashir M and Zaheer MS. Fixed Drug Eruption and Cross-reactivity Between Tinidazole and Metronidazole. International Journal of Dermatology; 1990; 29: 740.

13. Gupta R. Fixed Drug Eruption Due to Ornidazole. Indian J Dermatol. 2014 Nov-Dec; 59(6): 635.

14. Marya CM, Sharma G, Parashar VP, Dahiya V. Mucosal fixed drug eruption in a patient treated with ornidazole. J Dermatol Case Rep. 2012 Mar 27; 6(1):21-24.

15. Gupta S, Jain VK, Aggarwal K, Gupta S, Mahendra A. Fixed drug eruption caused by ornidazole. Contact Dermatitis.2005; 53:300-301.

16. Gupta S, Mahendra A, Gupta S, Kaur S. Multiple fixed drug eruption caused by ornidazole. Dermatitis.2010; 21:330333.

17. Naranjo CA, Busto U, Sellers EM, Sandor P, Ruiz I, Roborts EA. A method for estimating the probability of adverse drug reactions.ClinPharmacolTher; 1991; 30: 239-245.

18. Hartwig SC, Siegel J, Schneider PJ. Preventability and severity assessment in reporting adverse drug reactions. Am J Hosp Pharm; 1992; 49: 2229-32.

19.SharmaVK, DharS, GillAN.Drug related involvement ofspecific sites in fixed eruptions: a statistical evaluation .J Dermatol.1996Aug;23(8):530-534.

\section{How to cite this article?}

Sarkar M K, Mishra R, Pandya P, Bansal A, Bajhaiya B S, Mithun. Tinidazole-induced fixed drug eruption: A case report. Int J Med Res Rev 2015;3(7):777-780. doi: 10.17511/ijmrr.2015.i7.141. 